\title{
MEGARA main optics opto-mechanics
}

\author{
E. Castillo-Domínguez*a, J.L. Avilés ${ }^{\mathrm{a}}$, E. Carrasco ${ }^{\mathrm{a}}$, M. Maldonado ${ }^{\mathrm{b}}$, A. Gil de Paz ${ }^{\mathrm{c}}$, J. Gallego ${ }^{\mathrm{c}}$, \\ R. Cedazo ${ }^{\mathrm{d}}$, J. Iglesias ${ }^{\mathrm{e}} \&$ MEGARA team. \\ ${ }^{a}$ Instituto Nacional de Astrofísica, Óptica y Electrónica, Luis Enrique Erro No 1, Tonantzintla, \\ Puebla, Mexico; ${ }^{b}$ Fractal S.L.N.E. ${ }^{c}$ Universidad Complutense de Madrid, ${ }^{d}$ Universidad \\ Politécnica de Madrid, Instituto de Astrofísica de Andalucía-CSIC
}

\begin{abstract}
MEGARA is the future integral-field and multi-object spectrograph for the GTC $10.4 \mathrm{~m}$ telescope located in the Observatorio del Roque de los Muchachos in La Palma. INAOE is a member of the MEGARA Consortium and it is in charge of the Optics Manufacturing work package. In addition to the manufacturing of 73 elements, the work package includes the opto-mechanics i.e. the opto-mechanical design, manufacture, tests and integration of the complete assembly of the main optics composed by the collimator and camera subsystems. MEGARA passed the Optics Detailed Design Review in May 2013 and will have the Detailed Design Review of the complete instrument early 2014. Here we describe the detailed design of the collimator and camera barrels. We also present the finite elements models developed to simulate the behavior of the barrel, sub-cells and other mechanical elements. These models verify that the expected stress fields and the gravitational displacements on the lenses are compatible with the optical quality tolerances. The design is finished and ready for fabrication.
\end{abstract}

Keywords: Opto-mechanics, large optics, finite element analysis, tolerance analysis

\section{INTRODUCTION}

MEGARA (Multi-Espectrógrafo en GTC de Alta Resolución para Astronomía) ${ }^{1,2,3}$ is an instrument under development to be installed at GTC $10.4 \mathrm{~m}$ Telescope. It is a multi-object spectrograph (MOS) and integral field unit (IFU) in a single instrument. Figure 1 shows a model of the telescope and a close view of the spectrograph.

For operation, there is a set of robotic micro positioners for the MOS and an array of optical fibers forming the IFU ${ }^{4}$. The light gathered with the telescope, travels via fiber optics to the spectrograph located on one of the GTC platforms. The fiber bundle forms a pseudo slit ${ }^{5}$, the light carried out by the fibers from the focal plane of the telescope is collimated, then dispersed with one of the available volume phase holographic gratings (VPHs). The spectra is then refocused, by the camera, into a $4 \mathrm{~K}$ x $4 \mathrm{~K} \mathrm{CCD}$ cooled down $-100^{\circ} \mathrm{C}$ in a cryogenic chamber ${ }^{6,7,8}$. The collimator and camera have a set of mechanical supporting elements to hold the optical elements in place keeping the quality of the spectral image. A tolerance analysis was performed during the optical design to determinate the sensitivity of the system to changes in position and inclination. This sensitivity is the starting point to design the mechanical supports or opto-mechanics.

Bayar $^{9}$ explains the two main considerations for designing and building an opto-mechanical subsystem: the selected materials and the operating environment. The selected material for both sub-system is Aluminum 6061-T6 while the operation temperature range is from $-6^{\circ} \mathrm{C}$ to $30^{\circ} \mathrm{C}$ with a survival temperature range of $-15^{\circ} \mathrm{C}$ to $35^{\circ} \mathrm{C}$.

Typical approaches for large optics mounting use an elastomer for radial restriction and high precision mechanical components for axial restriction and tilt ${ }^{9,10,11}$. It is possible to substitute the elastomer for an Aluminum ring when the lenses are heavy as has been demonstrated by Farah ${ }^{11}$ and others. A defocusing in the image with a small change in position of lenses is expected due the fast F\#1.5 and the large temperature swing. This adds the necessity of a novel thermal compensator. The present works focuses on the design and validation of the opto-mechanical subsystem for the collimator and camera.

*cade@,inaoep.mx; phone +52 2222663100 ext 3405; http://guaix.fis.ucm.es/megara/

Ground-based and Airborne Instrumentation for Astronomy V, edited by

Suzanne K. Ramsay, lan S. McLean, Hideki Takami, Proc. of SPIE Vol. 9147,

91475R - (C) 2014 SPIE · CCC code: 0277-786X/14/\$18 · doi: 10.1117/12.2055251

Proc. of SPIE Vol. 9147 91475R-1 


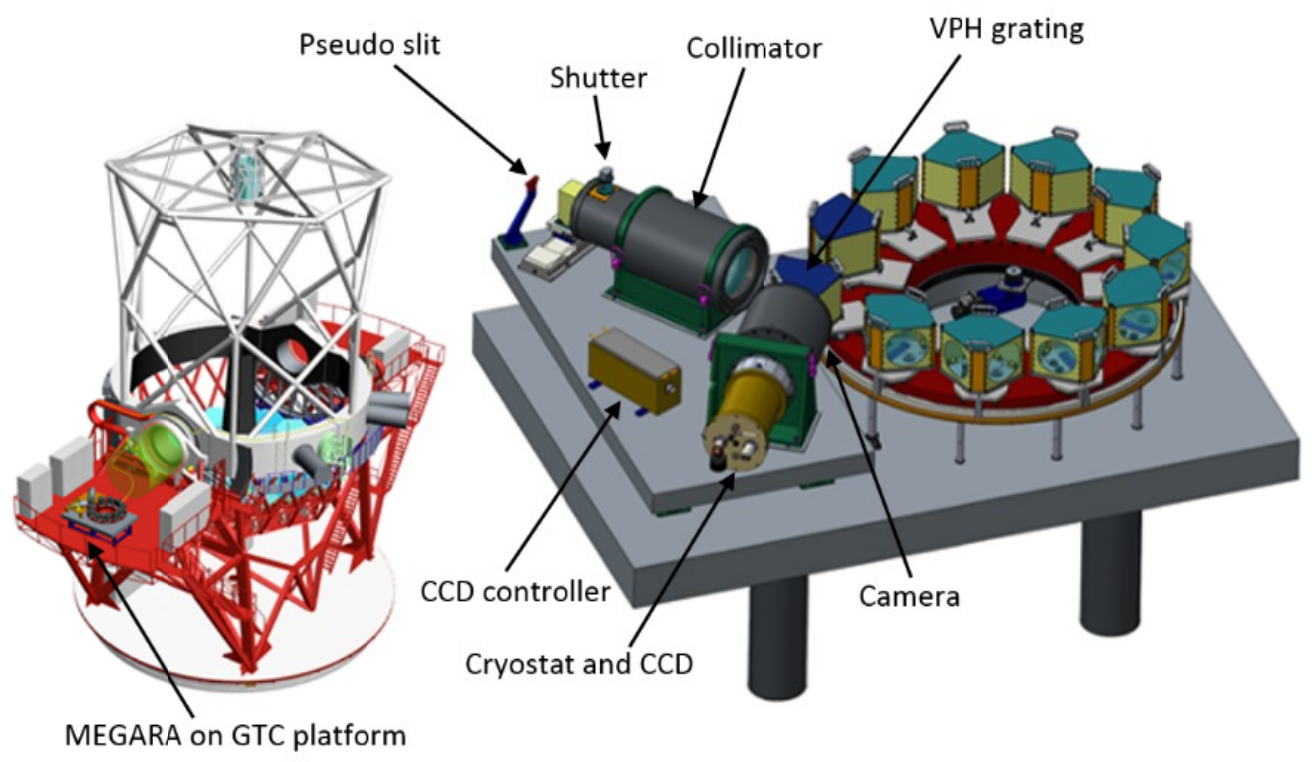

Figure 1: Left: MEGARA spectrograph installed on one of GTC Nasmyth platform. Right: close view of the spectrograph with its components. The optomechanical design presented in this paper corresponds to the collimator and camera subsystems.

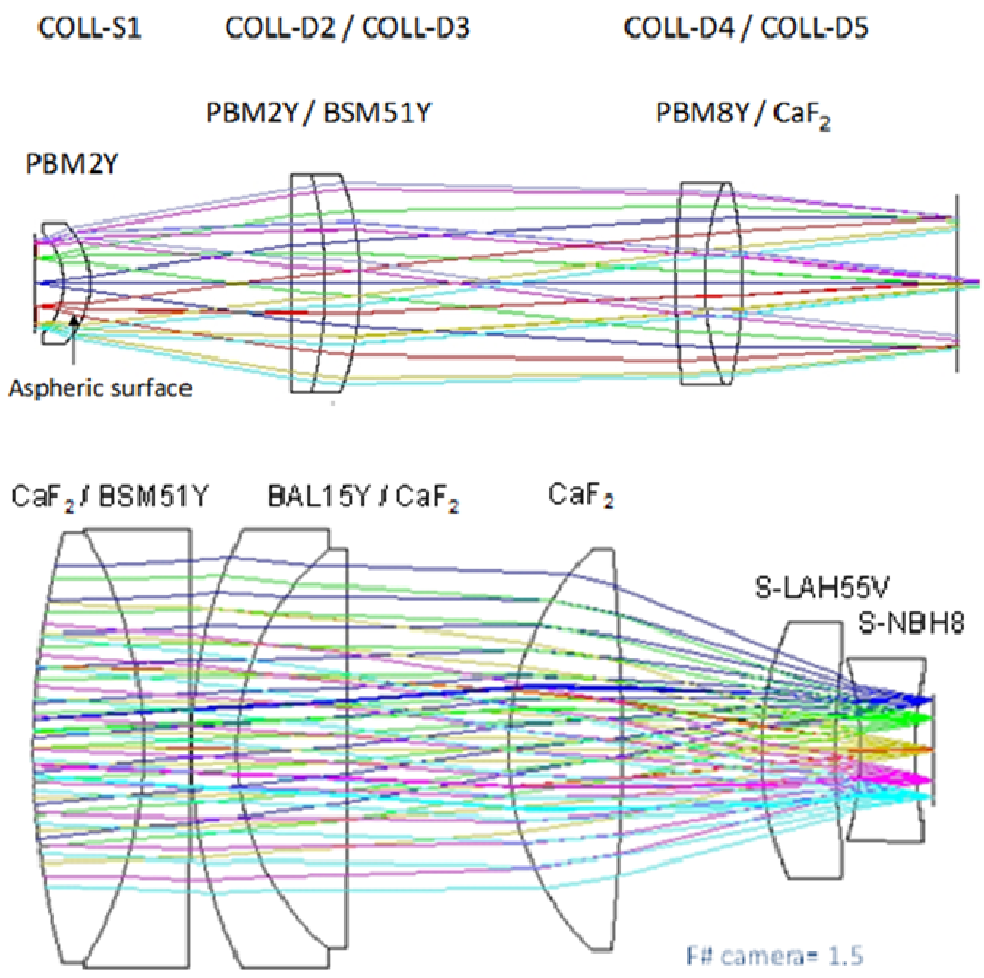

Figure 2: Collimator and camera optical layout. The materials of each element is indicated. The camera has a short F\#1.5. 


\section{PROPOSED DESIGN}

\subsection{Collimator}

The design of the opto-mechanics subsystems of the collimator and camera started with the optical designs. For the collimator there are two doublets and one singlet while the camera has two doublets and three singlets. Figure 2 shows the layout of both. Table 1 summarizes the main characteristics of two subsystems and Table 2 presents the tolerances in displacements and tilts for all components. Figure 3 shows a cut view of the two subsystems with their main parts indicated.

The collimator is a relatively simple barrel design with the cells sliding into the barrel. To simplify the manufacturing, the barrel is divided in three pieces: the large barrel holding the two doublets, a small barrel to host the singlet and the shutter and the third part is a flange to joint the two barrels. The collimator barrel is attached to the spectrograph optical bench with a custom support. It is comprised of four elements: the interface plate with two base brackets and a pair of clamps that press the main barrel against the support brackets with screws. In order to guarantee the co-linearity of the collimator optical axis with respect to the full system, both the barrel and the support structure are provided with a tolerated hole and a grinding pin.

The basic design of a sub-cell hosting an optical component is an Aluminum flexible ring cemented to the lens edge on three points using Scotch Weld 2216 epoxy adhesive. The exterior of the ring is fixed to the cell by six screws, this restricts the movement of the lens on radial direction while allows a flection with temperature. To avoid axial displacements, a pressure ring with a groove to contain an o'ring is screwed to the edge of the cell. The o'ring deformation was calculated to provide an equivalent force equal to 1.5 times the weight of the optical component. The applied force will assure the axial position of the lens over the temperature range. Figure 4 shows a cut view of an assembled cell and a flexible ring inserted on a lens.

Table 1: collimator and camera main optical characteristics.

\begin{tabular}{|l|l||l||}
\hline \multicolumn{1}{|c|}{ Characteristic } & \multicolumn{1}{c|}{ Collimator } & \multicolumn{1}{c|}{ Camera } \\
\hline Type & Refractive & Refractive \\
\hline Wavelength range & $370 \mathrm{~nm}-980 \mathrm{~nm}$ & $368 \mathrm{~nm}-950 \mathrm{~nm}$ \\
\hline F/\# & $\mathrm{F} / 3.03$ & F/1.54 \\
\hline Focal Length (@632.8nm) & $484.4 \mathrm{~mm}$ & $246.86 \mathrm{~mm}$ \\
\hline Entrance pupil & $160 \mathrm{~mm}$ diameter & $160 \mathrm{~mm}$ diameter \\
\hline Slit size & $119 \mathrm{~mm}$ length & $61.4 \mathrm{~mm} \mathrm{x} 61.4 \mathrm{~mm}$ \\
\hline Operating Temperature & $8.5^{\circ} \mathrm{C}$ & $8.5^{\circ} \mathrm{C}$ \\
\hline
\end{tabular}

\subsection{Camera}

The camera has a more complex design due the necessity of athermalization driven by the large temperature swing and the short F\#. To address this issue, a double concentric barrel design was selected. The inner barrel holds the sub-cells while it is hanging from the external barrel with two Titanium flexures. The main barrel encloses the inner barrel firmly on the horizontal and vertical axes (X, Y) while allows a spring controlled movement along the optical axis (Z).

The camera barrel opto-mechanical design is based on the optical tolerance analysis and previous design ${ }^{13,5}$ from the MEGARA team. From the analysis it was decided to use CAM-S6 as a thermal compensator by controlling its axial distance from CAM-S7 and from the block formed by CAM-S5 and the preceding optics, which should move together with respect to CAM-S6. Thus, with temperature increments, these distances variations must be larger than those that correspond to the Aluminum dilatation $\left(23 \mu \mathrm{m}\right.$ per meter per $\left.{ }^{\circ} \mathrm{C}\right)$. 
Table 2: Tolerances for position and tilt of each optical component.

\begin{tabular}{|c|c|c|c|c|}
\hline L\# & Optical element & (Displacement X,Y) & $\mathbf{( Z )}$ & Tilt \\
\hline 1 & Singlet (aspheric, COLL-S1) & \pm 300 & $\boldsymbol{\mu m}$ & arc minutes \\
\hline 2 & Doublet 1, COLL-D2 /COLL-D3 & \pm 300 & \pm 100 & 2.1 \\
\hline 3 & Doublet 2, COLL-D4 /COLL-D5 & \pm 300 & \pm 100 & 2.1 \\
\hline 4 & Doublet 1, CAM-D1/CAM-D2 & \pm 150 & \pm 100 & 2.1 \\
\hline 5 & Doublet 2, CAM-D3/CAM-D4 & \pm 150 & \pm 100 & 2.1 \\
\hline 6 & Singlet 1, CAM-S5 & Compensator & \pm 100 & 2.1 \\
\hline 7 & Singlet 2, CAM-S6 & \pm 150 & \pm 100 & 2.1 \\
\hline 8 & Singlet 3, CAM-S7 & \pm 150 & \pm 100 & 2.1 \\
\hline
\end{tabular}
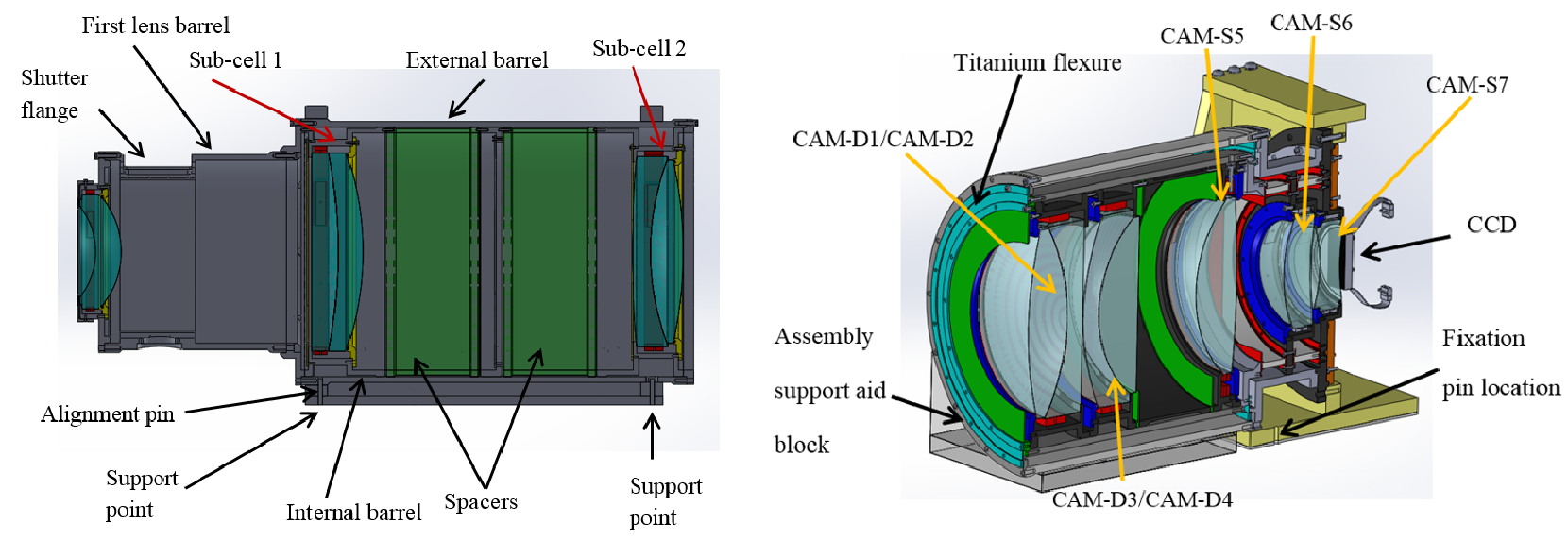

Figure 3: Collimator and camera opto-mechanical subsystems with the optical elements set in place.

For the a-thermal operation CAM-S6 mount is attached to a high coefficient of thermal expansion (CTE) polymer (PTFE or polymaq $^{\circledR}$ ) cylinder on both sides. On one side is screwed to the interface plate that is also the mount of CAM-S7. Therefore, with a temperature increment the mount of CAM-S6 will separate from CAM-S7 a larger distance than the corresponding section of the outer barrel. The polymer ring on the other side of CAM-S6 mount is screwed to the inner barrel. The idea is that CAM-S5 and the preceding optics will also separate the same distance from CAM-S6 i.e. then, CAM-S5 will separate twice as much from CAM-S7. 

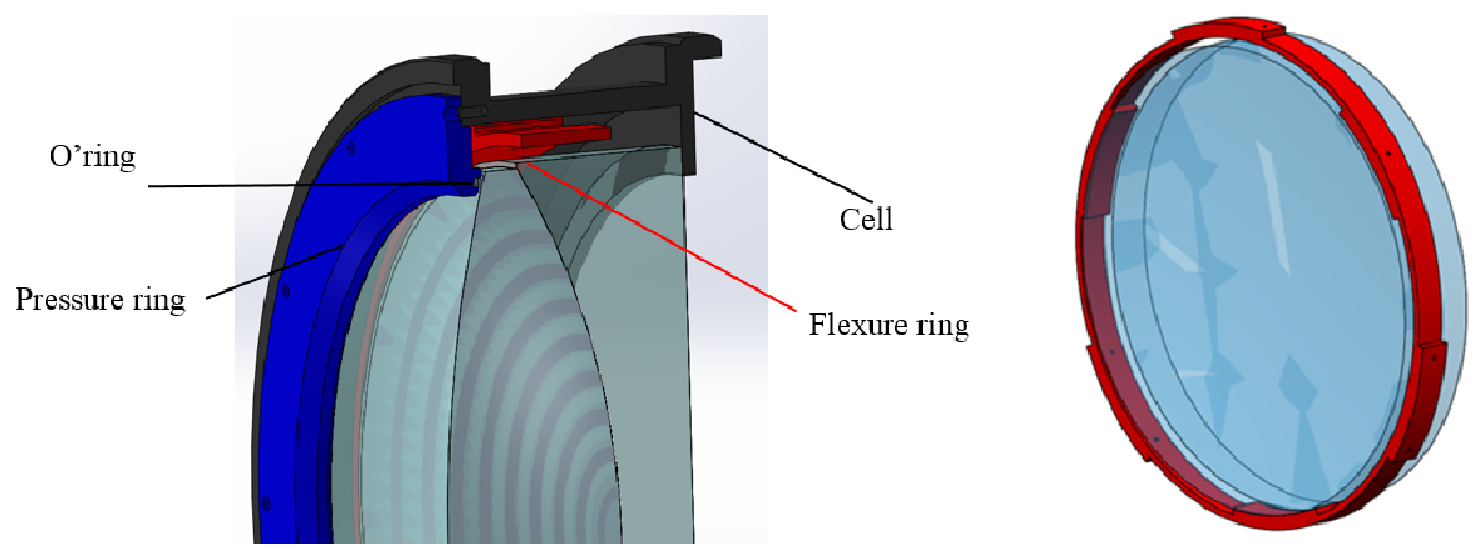

Figure 4: Left: sub-cell detail view. The mechanism starts with a doublet: a flexible ring glue to one lens edge supports the lenses radially. The axial support is provided on one side by the mount and on the other side by a pressure ring which holds an o'ring to make contact on the optical surface and keep it in place. Right: a lens with a flexible ring attached. The ring will be glued to the lens edge $b$ using Scotch weld 2216 epoxy adhesive.

The doublets and CAM-S5 sub-cells are mounted in a common "inner" barrel. This should move as a whole when is "pushed" by the polymer ring as it expands due to the thermal dilatation. But the polymer is too soft to handle all the weight of the optics and opto-mechanics that need to be moved, so the weight is carried by the outer barrel. To accomplish this, the inner barrel is joined to the outer barrel with a circular flexure (diaphragm) to be able to move freely on the axial direction but restricted in the radial direction.

CAM-S5 is used also as a compensator in the radial direction. For this reason, instead of being mounted in a radial flexure like the other lenses, it is mounted in a double flexible aluminum ring that works as a double flexure. Three screws that are inserted from the outside of the barrel are screwed on the zone that connects both rings. The deformation of the ring allows a precise $\mathrm{X}-\mathrm{Y}$ movement of the lens center, maintaining its stiffness. Figure 5 shows CAM-S5 double flexible ring and the polymer ring section of the camera. Figure 6 shows CAM-S5 mount inserted in the inner barrel and the spacer, the Titanium flexures can be appreciated.
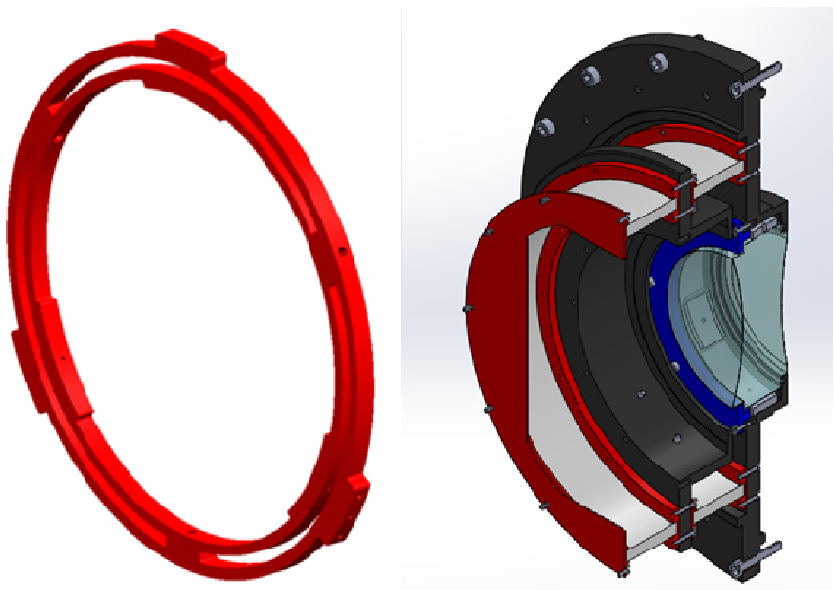

Figure 5: Left: CAM-S5 double flexible ring. Right: cut view of CAM-S6 and CAM-S7 mounted in their cells including the polymer rings to compensate the thermal expansion-contraction. 
In the final design, the flexures are made of Ti6Al4V titanium alloy with $0.4 \mathrm{~mm}$ thickness on $3 \mathrm{~mm}$ wide end rings. The attachment to the optical bench is be made of 6061-T6 Aluminum alloy. It follows the same principle of manufacturing than the collimator interface structure i.e. it will be manufactured by sections as shown in Figure 3.

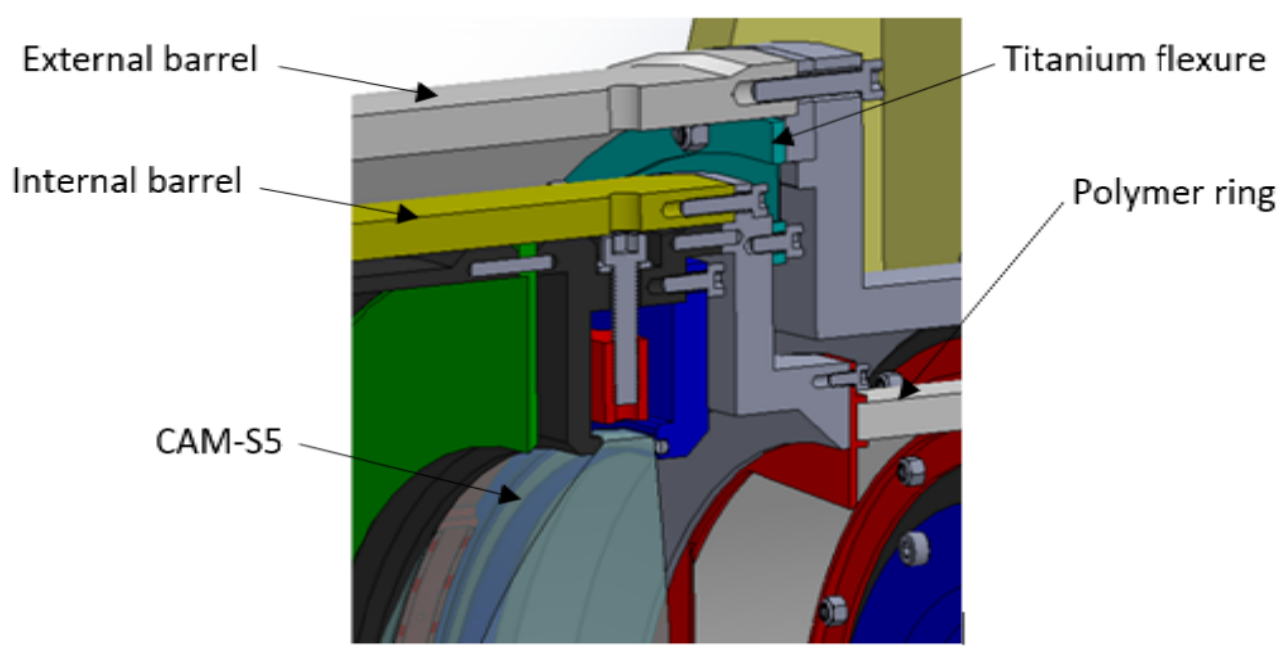

Figure 6: The mount for CAM-S5 is inserted in the inner barrel and the spacer.

\section{VALIDATION}

As mentioned, the structural design of the different subsystems was approached by taking into account the effect of static deformations expected either along the handling process or during the observing time at the telescope. Physical properties of the optical components may be affected by environmental factors such as the working temperature or gravity load itself. For example, to micrometrical scales, for some materials, the value of several properties is affected when the body of the lens is stretched or expanded due to thermal dilatation under restricted room. This is the case of the refraction index, which, under some circumstances, is affected when an optical element is exposed to mechanical stress by its radial support, giving rise to birefringence and, in a catastrophic scenario, to reach the glass breaking point. Another very sensible property is the relative position of a given optical component, influenced by both: gravity load and the structural thermal dilatation.

In order to guarantee the opto-mechanical performance of the camera and the collimator subsystems, we analyzed the gravity deflections and the stress fields acting on each optical element. The analysis was made under a set of four intervals of thermal variation. The ranges are selected from the operation, degraded operation and survival temperatures. They are ranging from $20^{\circ} \mathrm{C}$ to $30^{\circ} \mathrm{C}\left(\Delta \mathrm{t}=10^{\circ} \mathrm{C}\right), 20^{\circ} \mathrm{C}$ to $8.5^{\circ} \mathrm{C}\left(\Delta \mathrm{t}=-11.5^{\circ} \mathrm{C}\right), 20^{\circ} \mathrm{C}$ to $-2{ }^{\circ} \mathrm{C}\left(\Delta \mathrm{t}=-22{ }^{\circ} \mathrm{C}\right)$ and $20^{\circ} \mathrm{C}$ to $6^{\circ} \mathrm{C}\left(\Delta \mathrm{t}=-26^{\circ} \mathrm{C}\right)$.

The analysis of the gravity deflections was mainly concerned with observing the incremental change of a set of known points belonging to the body of a given lens along the vertical direction. The value of seven spatial parameters is evaluated, all of them sensibly influenced by the combined effect of three environmental and physical factors: temperature, volume and weight of the optical elements. These seven parameters are: the displacements observed along each of the three reference axis $\Delta \mathrm{x}, \Delta \mathrm{y}, \Delta \mathrm{z}$; the angular displacements observed around each one of the same axial references Фx, Фy, Фz; and the mechanical stress. Figure 7 shows the mesh distribution and the nodes for the analysis of the collimator and camera subsystems. 


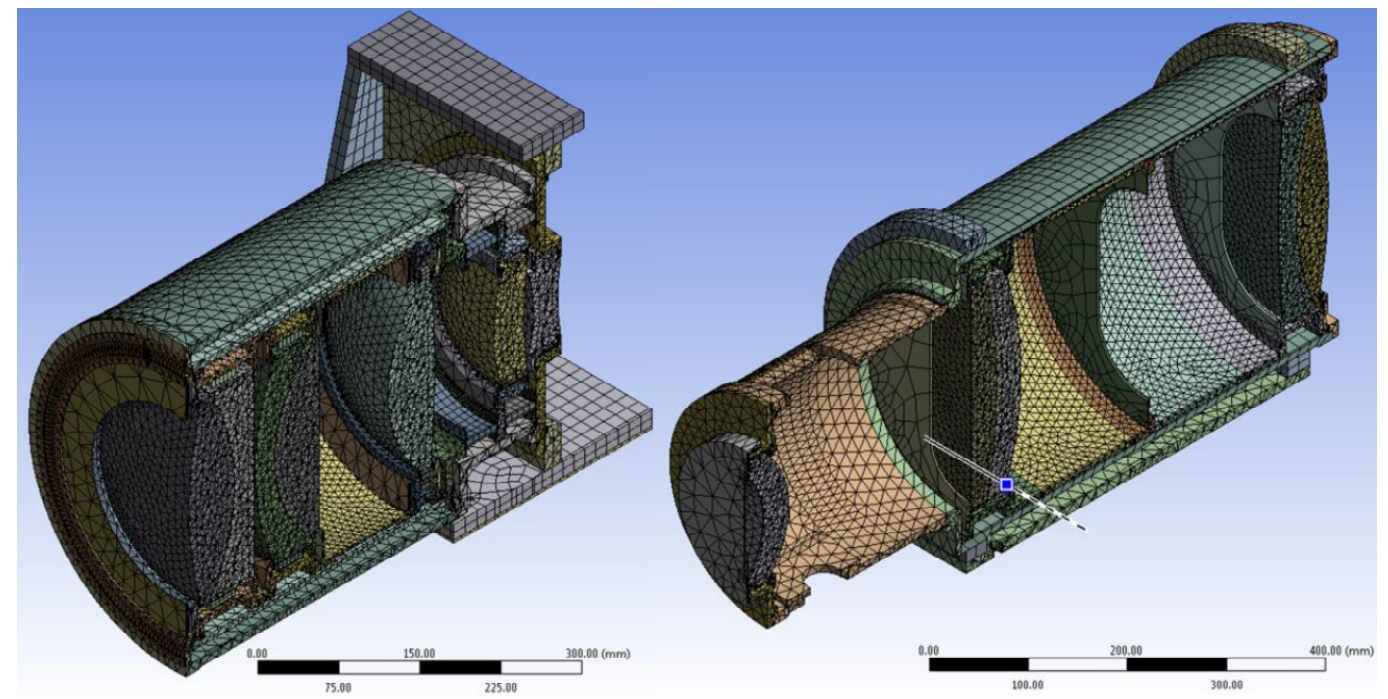

Figure 7: Cut views of collimator -right- and camera -left- with the details of mesh for finite element analysis. Both subsystems were analyzed by taking into account the optical elements.

In the following subsections we show the results of the Finite Element Analysis (FEA) performed on the computer-aided design (CAD) model of both opto-mechanical subsystems. The FEA was performed using the engineering simulation software ANSYS. The lens position displacements and tilts were computed from the displacement on the vertex and the four cardinal points on the surface of each lens.

\subsection{Collimator}

The total displacement observed along the vertical direction $\Delta \mathrm{y}$, corresponding to the thermal variation of $20{ }^{\circ} \mathrm{C}$ to 8.5 ${ }^{\circ} \mathrm{C}\left(\Delta \mathrm{t}=-11.5^{\circ} \mathrm{C}\right)$ is shown in Figure 8 . The scale, ranging from 0.0 to $0.20037 \mathrm{~mm}$, the minimum value in the darkest color. As expected, radial pattern, centered on the fixation pin, is observed due to the increasing value of the $\Delta y$ displacement. The maximum computed value corresponds to the point labeled as MAX, located at the upper right corner. The FEA result is consistent with expected displacement. For each of the four intervals of thermal variation, the displacements of each lens are summarized in the Table 3.

Regarding the stress, the results obtained for the same thermal variation are shown in Figure 9. As expected, the maximum stress is located at those zones where the lenses are held by the corresponding flexure ring. The stress level spans $0.7019 \mathrm{MPa}$ at the edges, which is not large enough to produce birefringence. 


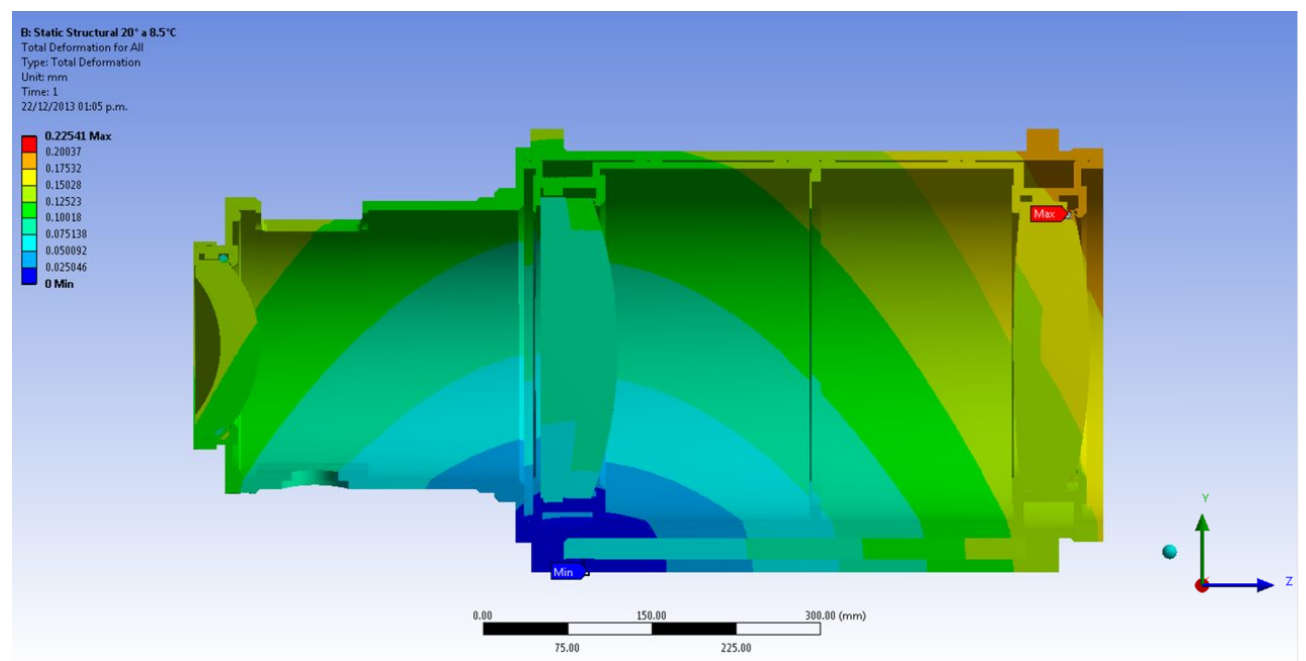

Figure 8. Example of FEA gravity analysis results. It shows the whole system bending over its own weight. It includes gravity and temperature changes. The color scale is in $\mathrm{mm}$.

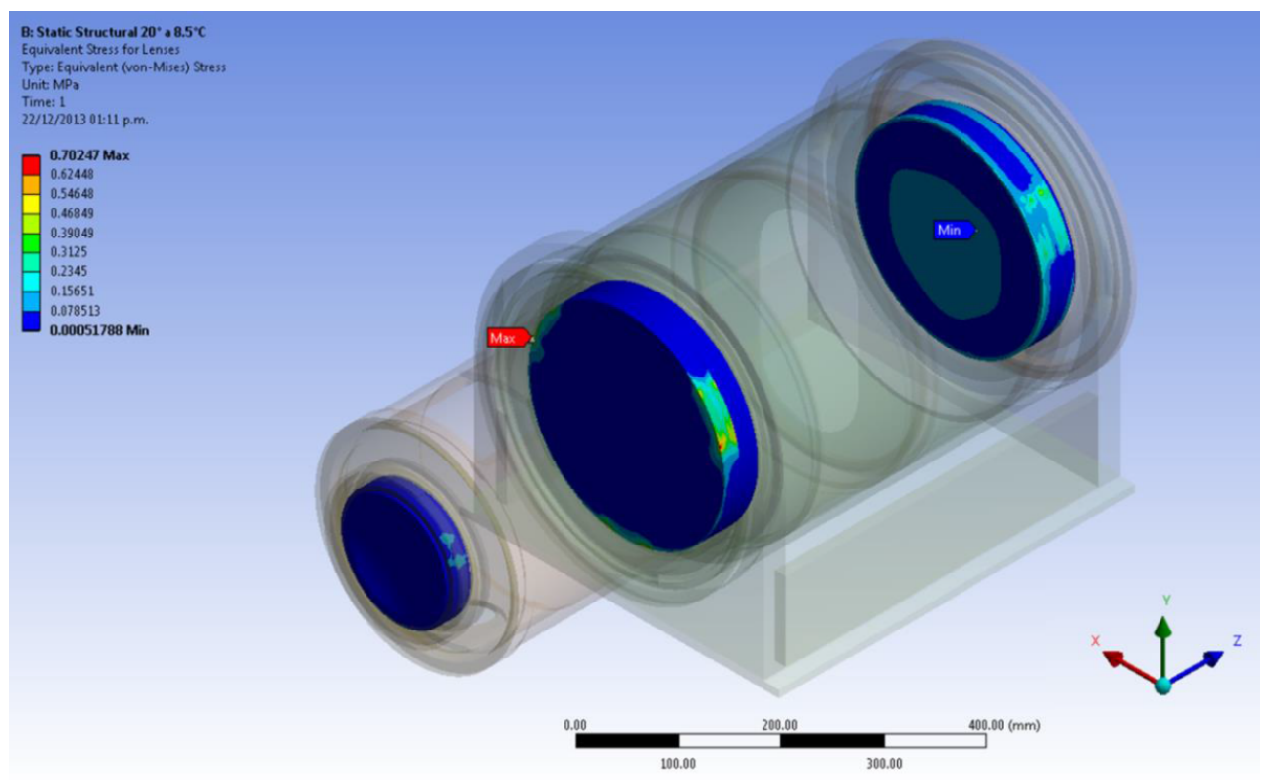

Figure 9. Stress on the optical components of collimator. The stress on the rest of the structure was calculated but removed in the figure for clarity. In any case the maximum stress is smaller than $0.8 \mathrm{MPa}$ in the edges. The color scale is in MPa ranging from 0.00051788 to 0.70247 . 
Table 3: Results of displacement and rotations on all collimator optical components. The values were calculated from FEA.

\begin{tabular}{|c|c|c|c|c|c|c|c|c|c|c|c|c|c|}
\hline \multicolumn{14}{|c|}{ Displacement and rotation of lenses for different temperature intervals: } \\
\hline \multicolumn{7}{|c|}{$20^{\circ} \mathrm{C}$ to $8.5^{\circ} \mathrm{C}$} & \multicolumn{7}{|c|}{$20^{\circ} \mathrm{C}$ to $-2^{\circ} \mathrm{C}$} \\
\hline \multirow[t]{2}{*}{ Lens } & $\Delta \mathbf{x}$ & $\Delta \mathbf{y}$ & $\Delta \mathbf{z}$ & $\Phi \mathbf{\Phi}$ & Фy & $\Phi \mathbf{\Phi}$ & $\Delta \mathbf{x}$ & $\Delta \mathbf{y}$ & $\Delta$ & & $\Phi \mathbf{\Phi}$ & Фy & $\Phi \mathbf{\Phi z}$ \\
\hline & \multicolumn{3}{|c|}{$\mu \mathrm{m}$} & \multicolumn{3}{|c|}{ arc sec } & \multicolumn{4}{|c|}{$\mu \mathrm{m}$} & \multicolumn{3}{|c|}{$\operatorname{arcsec}$} \\
\hline $\begin{array}{c}\text { COLL- } \\
\text { S1 }\end{array}$ & 0.06 & -71.45 & 105.31 & -1.09 & 0.03 & 0.37 & 0.078 & -122.5 & 187 & & -1.28 & 0.04 & 0.65 \\
\hline $\begin{array}{c}\text { COLL- } \\
\text { D2 }\end{array}$ & -0.05 & -82.77 & 9.53 & -0.28 & 0.02 & 0.02 & -0.102 & -133.4 & 17. & & -0.45 & 0.03 & 0.03 \\
\hline $\begin{array}{c}\text { COLL- } \\
\text { D4 } \\
\end{array}$ & -0.04 & -72.16 & -126.49 & -1.15 & 0.08 & -0.04 & -0.1 & -122.84 & -224 & & -1.45 & 0.10 & -0.06 \\
\hline \multicolumn{7}{|c|}{$20^{\circ} \mathrm{C}$ to $-6^{\circ} \mathrm{C}$} & \multicolumn{7}{|c|}{$20^{\circ} \mathrm{C}$ to $30^{\circ} \mathrm{C}$} \\
\hline \multirow[t]{2}{*}{ Lens } & $\Delta \mathbf{x}$ & $\Delta \mathbf{y}$ & $\Delta \mathbf{z}$ & $\Phi \mathbf{x}$ & Фy & $\Phi \mathbf{z}$ & $\Delta \mathbf{x}$ & $\Delta \mathbf{y}$ & $\Delta \mathbf{z}$ & $\Phi \mathbf{~}$ & & Dy & $\Phi \mathbf{z}$ \\
\hline & \multicolumn{3}{|c|}{$\mu \mathrm{m}$} & \multicolumn{3}{|c|}{$\operatorname{arcsec}$} & \multicolumn{3}{|c|}{$\mu \mathrm{m}$} & \multicolumn{4}{|c|}{$\operatorname{arcsec}$} \\
\hline $\begin{array}{c}\text { COLL- } \\
\text { S1 }\end{array}$ & 0.09 & -141.84 & 219.07 & -1.28 & 0.04 & 0.77 & -0.04 & 32.49 & -65.09 & -1.12 & & .03 & -0.19 \\
\hline $\begin{array}{c}\text { COLL- } \\
\text { D2 }\end{array}$ & -0.10 & -152.82 & 20.38 & -0.44 & 0.04 & 0.03 & -0.06 & 21.26 & -8.16 & -0.30 & & .03 & -0.007 \\
\hline $\begin{array}{c}\text { COLL- } \\
\text { D4 }\end{array}$ & -0.12 & -142.21 & -262.17 & -1.47 & 0.11 & -0.07 & 0.06 & 31.82 & 71.63 & -0.99 & & 024 & 0.007 \\
\hline
\end{tabular}

The analysis shows that all components are within specifications, even in the worst case scenario. The maximum displacement is -260 micron including all applicable parameter, the maximum allowable is 300 micron, according to the tolerances defined for assembly, integration and verification (AIV). There are positive and negative displacements on the $\mathrm{Z}$ axis. This is due to the fact that pin that defines the position of the collimator base respect to the optical table is close to the position of COLL-D2/COLL-D3, few millimeters towards COLL-S1; this cause a positive displacement of COLL-S1 and a negative displacement of COLL-D4/COLL-D5. For the case of rotations, the FEA results shows a maximum of 1.47 arc seconds while the requirements table admits up to 126 arc seconds.

\subsection{Camera}

Figure 10 shows a representation of the $\Delta y$ displacements due to gravity loads and a differential change in temperature $\Delta \mathrm{t}=-11.5{ }^{\circ} \mathrm{C}$ (from 20 to $8.5{ }^{\circ} \mathrm{C}$ ). The whole deformation is shown in a linear scale ranging from 0.0 to 0.21358 millimeters. As in the case of the collimator subsystem, a radial like pattern is observed with the origin matching the fixation pin (the darkest zone). The maximum deformation is observed at the most distant zone form the fixation pin. A detailed list of the displacements for each lens according to the FEA simulation is shown in Table 4.

The analysis shows that all components are within specifications, even in the worst case scenario. The maximum displacement obtained is -176.72 micron including all applicable parameter. The maximum allowable is \pm 150 micron. To solve the excess of bending, a lift of 75-100 micron will correct the position. There are positive and negative displacements on $\mathrm{Z}$ axis, this is due to the fact that the pin that defines the position of the camera base, respect to the optical table, is close to the position of CAM-S6; this cause a positive displacement of CAM-S7 when cooling, and a negative displacement of CAM-S5 due to the different CTE. For the case of rotations, the FEA results shows maximum rotations $\sim 19$ arc seconds while the requirements table admits up to 126 arc seconds. 


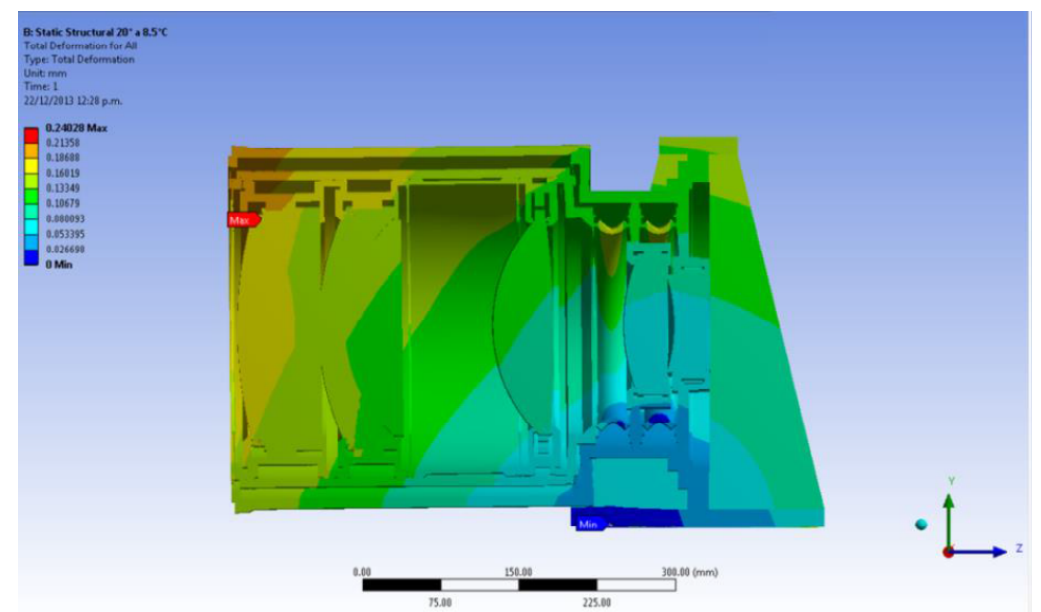

Figure 10. Structural deformation due gravity, temperature changes and o'ring applied forces

Table 4: Results of displacements and rotations of all optical components of camera. The values were calculated from FEA results.

\begin{tabular}{|c|c|c|c|c|c|c|c|c|c|c|c|c|}
\hline \multicolumn{13}{|c|}{ Displacement and rotation of lenses for different temperature intervals: } \\
\hline \multicolumn{7}{|c|}{$20^{\circ} \mathrm{C}$ to $8.5^{\circ}$} & \multicolumn{6}{|c|}{$20^{\circ} \mathrm{C}$ to $-2^{\circ} \mathrm{C}$} \\
\hline \multirow[t]{2}{*}{ Lens } & $\Delta \mathrm{x}$ & $\Delta \mathrm{y}$ & $\Delta \mathrm{z}$ & $\Phi x$ & Фу & $\Phi z$ & $\Delta \mathrm{x}$ & $\Delta \mathrm{y}$ & $\Delta \mathrm{z}$ & $\Phi \mathrm{x}$ & Фу & $\Phi z$ \\
\hline & \multicolumn{3}{|c|}{$\mu \mathrm{m}$} & \multicolumn{3}{|c|}{ Arc sec } & \multicolumn{3}{|c|}{$\mu \mathrm{m}$} & \multicolumn{3}{|c|}{ Arc sec } \\
\hline $\begin{array}{c}\text { CAM- } \\
\text { D1 }\end{array}$ & -0.14 & -101.5 & 142.5 & -6.52 & 0.61 & -0.05 & -0.22 & -153.43 & 255.2 & -6.10 & 0.59 & -0.06 \\
\hline $\begin{array}{c}\text { CAM- } \\
\text { D3 }\end{array}$ & -0.72 & -94.29 & 103.6 & -10.37 & 0.37 & -0.001 & -0.76 & -148.92 & 185.4 & -8.331 & 0.36 & -0.01 \\
\hline CAM-S5 & 0.09 & -90.65 & 68.57 & -18.94 & 0.20 & -0.07 & 0.075 & -147.18 & 122.1 & -16.41 & 0.16 & -0.10 \\
\hline CAM-S6 & -0.42 & -78.23 & 8.13 & -4.36 & 0.19 & -0.28 & -0.38 & -136.48 & 15.64 & -1.91 & 0.29 & -0.35 \\
\hline CAM-S7 & 0.02 & -75.91 & -11.11 & 3.25 & 0.14 & 0.24 & -0.0007 & -134.94 & -31.6 & 5.63 & 0.12 & 0.38 \\
\hline \multicolumn{7}{|c|}{$20^{\circ} \mathrm{C}$ to $-6^{\circ} \mathrm{C}$} & \multicolumn{6}{|c|}{$20^{\circ} \mathrm{C}$ to $30^{\circ} \mathrm{C}$} \\
\hline \multirow[t]{2}{*}{ Lens } & $\Delta \mathrm{x}$ & $\Delta \mathrm{y}$ & $\Delta \mathrm{z}$ & $\Phi x$ & Фy & $\Phi z$ & $\Delta \mathrm{x}$ & $\Delta \mathrm{y}$ & $\Delta \mathrm{z}$ & $\Phi \mathrm{x}$ & Фу & $\Phi z$ \\
\hline & \multicolumn{3}{|c|}{$\mu \mathrm{m}$} & \multicolumn{3}{|c|}{ Arc sec } & \multicolumn{3}{|c|}{$\mu \mathrm{m}$} & \multicolumn{3}{|c|}{ Arc sec } \\
\hline $\begin{array}{c}\text { CAM- } \\
\text { D1 }\end{array}$ & -0.20 & -176.7 & 297.39 & -6.84 & 0.62 & -0.07 & -0.069 & 18.09 & -70.35 & -2.77 & 0.30 & -0.01 \\
\hline $\begin{array}{c}\text { CAM- } \\
\text { D3 }\end{array}$ & -0.75 & -172.3 & 215.65 & -8.92 & 0.38 & -0.01 & -0.57 & 26.87 & -47.97 & -8.01 & 0.22 & 0.02 \\
\hline CAM-S5 & 0.08 & -170.2 & 142.11 & -16.82 & 0.20 & -0.117 & 0.11 & 29.3 & -27.28 & $\begin{array}{l}-17.78 \\
\end{array}$ & 0.24 & -0.02 \\
\hline CAM-S6 & -0.37 & -159.2 & 21.04 & -2.21 & 0.33 & -0.38 & -0.47 & 41.06 & 10.59 & -2.91 & 0.14 & -0.17 \\
\hline CAM-S7 & $\begin{array}{l}-0.01 \\
\end{array}$ & -157.6 & -41.93 & 5.11 & 0.10 & 0.43 & 0.07 & 43.31 & 34.65 & 4.72 & 0.18 & -0.03 \\
\hline
\end{tabular}


A graphical representation of the stress analysis is shown in the Figures 11 and 12. Figure 11 shows that the maximum strain level is taking place at the edges of the lenses, where these are held by the corresponding flexure ring. Figure 12 shows that the clear aperture is free of strain larger than $2 \mathrm{MPa}$. As in the case of the collimator, the strain span is shown in a linear scale, ranging in this case from 0.0011495 to $3.1233 \mathrm{MPa}$ for both figures. The outer zone of the clear aperture in Figure 12 is barely affected by a stress of $0.69496 \mathrm{MPa}$.

The expected average-operation temperature for MEGARA is $8{ }^{\circ} \mathrm{C}$, the Regular operation range is from 19 to $-2{ }^{\circ} \mathrm{C}$ and the degraded operation was defined as two intervals ranging from 19 to $-6{ }^{\circ} \mathrm{C}$ and 20 to $30^{\circ} \mathrm{C}$. Our results show that the contact between the flexible ring and the lens is free of stress at the nominal operation temperature.

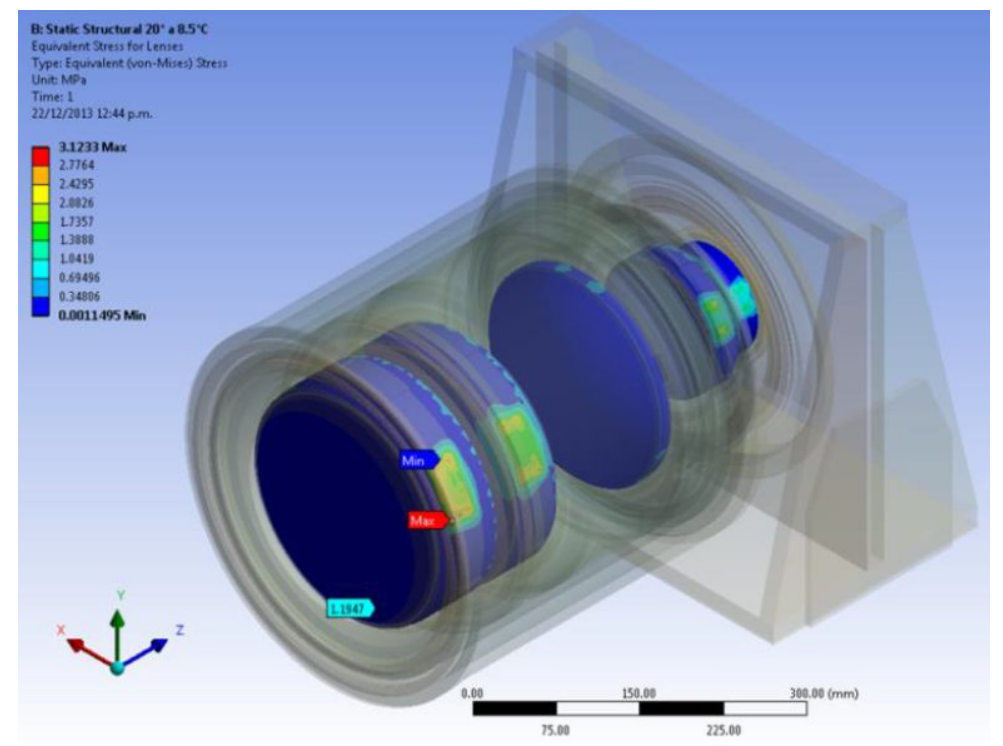

Figure 11. Strain levels on the optical components. The maximum of $3.12 \mathrm{MPa}$ is only on a small part of the edge of lenses.

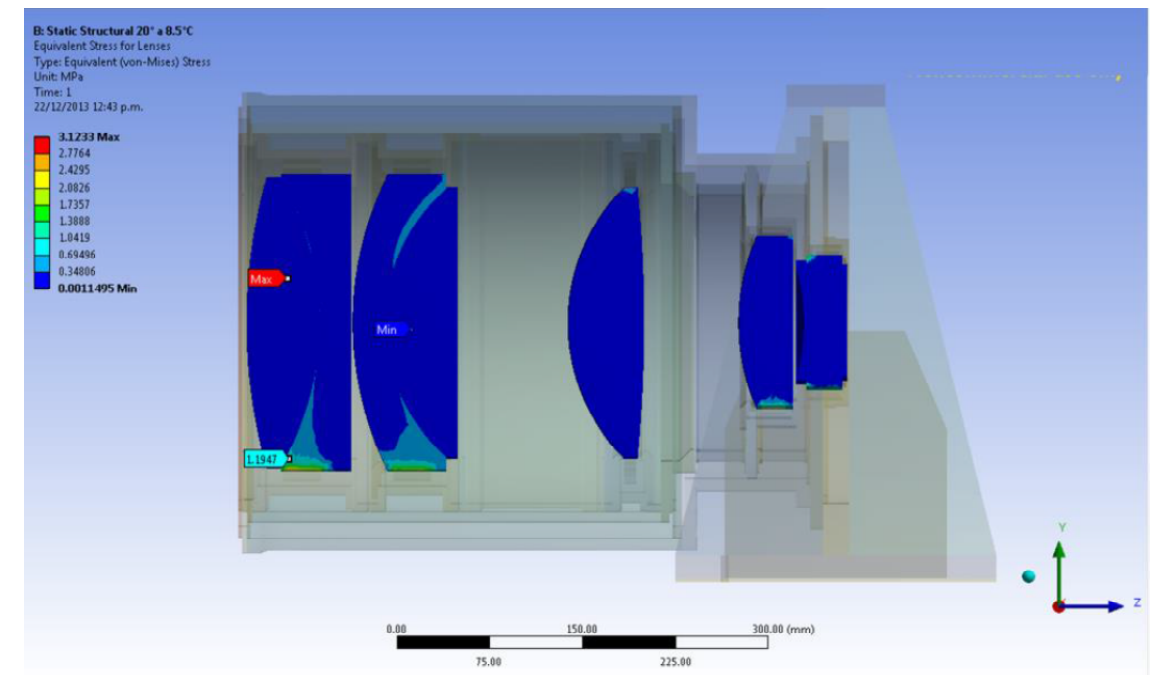

Figure 12. Cut view of the total strain results to see that internally the strain on the clear aperture is not larger than $2 \mathrm{MPa}$. 


\section{MECHANICAL TOLERANCE ANALYSIS}

All machined parts have mechanical uncertainties on their dimensions due to the manufacturing process. The critical dimensions are those related to the positioning and inclinations i.e.:

- Diameter and circularity. It is related directly to the optical axis alignment between the optical components on the plane orthogonal to the optical axis (X and $\mathrm{Y}$ for the case of MEGARA).

- Separation. In the camera, the separation between components is essential to keep the focus on the image plane (Z) due the small F\#.

- Flatness. If this fails, the optical component will be tilted respect to the optical axis and the whole system could misbehave or, at least, degrade its functionality.

Table 2 contains the maximum allowable miss position of each component. From this, the fabrication tolerances for the critical pieces were extracted dividing the maximum acceptable tolerance by the square root of the sum of the number of fits for each component:

$$
U_{N}=\frac{\operatorname{Tol}_{\max }}{\sqrt{N}}
$$

For the tilt analysis only takes into account the flatness of the lens seat. Given the lens radius $\left(\mathrm{L}_{\mathrm{r}}\right)$ and the maximum acceptable tilt $(\varnothing)$, the maximum allowable flatness error with be:

$$
E_{f}=L_{r} x \tan (\varnothing)
$$

The assumptions used for the tolerance calculations are:

1. The main barrels of each subsystem, collimator and camera, are the reference. This is because any uncertainty between the barrel and the supporting table can be eliminated moving up or tilting the whole barrel.

2. The mechanical junctions, called fits on this work, are similar.

3. The fits are uncorrelated. This allows using the square root of the sum of the fits as the expected accumulated value.

4. There are 3 fits between the barrel and the optical components in them. The case of collimator is straight forward but the camera is not. In the camera case we assume that because there are six centering screws which allow centering perfectly the inner barrel with the external barrel.

Table 5 resumes the results of all tolerance calculations. There are two very tight requirements on CAM-D1/CAM-D2 and CAM-D3/CAM-D4 for $\mathrm{Z}$ axis. There is a compensator (CAM-S5) to solve this problem, however, the final machining will be done when all related pieces are terminated and the as-built dimensions are available.

This analysis was used to set the tolerances on the manufacturing drawings which are already finished. 
Table 5: Tolerance analysis results. The two first columns are for diameters of concentric pieces, the third one is the flatness of mating flanges and last one is the flatness of the lens seat flange.

\begin{tabular}{|c|c|c|c|c|c|}
\hline \multirow{2}{*}{ L\# } & \multirow{2}{*}{ Optical element } & \multicolumn{4}{|c|}{ Tolerances } \\
\hline & & Shaft $(\mu \mathrm{m})$ & Hole $(\mu \mathrm{m})$ & $\mathrm{Z}$ axis $(\mu \mathrm{m})$ & Tilt $(\mu \mathrm{m})$ \\
\hline 1 & Singlet (aspheric, COLL-S1) & $\begin{array}{l}-20 \\
-70\end{array}$ & $\begin{array}{r}+20 \\
+70\end{array}$ & \pm 50 & \pm 47 \\
\hline 2 & Doublet 1, COLL-D2 /COLL-D3 & $\begin{array}{l}-20 \\
-90\end{array}$ & $\begin{array}{r}+20 \\
+90\end{array}$ & \pm 57 & \pm 82 \\
\hline 3 & Doublet 2, COLL-D4 /COLL-D5 & $\begin{array}{l}-20 \\
-90\end{array}$ & $\begin{array}{r}+20 \\
+90\end{array}$ & \pm 37 & \pm 76 \\
\hline 4 & Doublet 1, CAM-D1/CAM-D2 & $\begin{array}{l}-20 \\
-50\end{array}$ & $\begin{array}{r}+20 \\
+50\end{array}$ & \pm 25 & \pm 73 \\
\hline 5 & Doublet 2, CAM-D3/CAM-D4 & $\begin{array}{l}-20 \\
-50\end{array}$ & $\begin{array}{r}+20 \\
+50\end{array}$ & \pm 26 & \pm 73 \\
\hline 6 & Singlet 1, CAM-S5 & $\begin{array}{l}-20 \\
-50\end{array}$ & $\begin{array}{r}+20 \\
+50\end{array}$ & \pm 31 & \pm 67 \\
\hline 7 & Singlet 2, CAM-S6 & $\begin{array}{l}-20 \\
-40\end{array}$ & $\begin{array}{l}+20 \\
+40\end{array}$ & \pm 44 & \pm 43 \\
\hline 8 & Singlet 3, CAM-S7 & $\begin{array}{l}-20 \\
-40\end{array}$ & $\begin{array}{l}+20 \\
+40\end{array}$ & \pm 100 & \pm 33 \\
\hline
\end{tabular}

\section{CONCLUSSIONS}

The opto-mechanical design at Critical Design Review level (CDR) is finished, including the manufacturing drawings with tolerances. An exhaustive finite element analysis was performed for the collimator and camera subsystems. The FEA results show that the opto-mechanical design do not degrade the optical performance of the spectrograph. The opto-mechanical performance for different temperature intervals are within the AIV tolerances. For the AIV process a temperature-controlled lab especially dedicated to assemble the MEGARA opto-mechanics is being prepared at INAOE.

The design of the opto-mechanics for optical system of such large diameter with the required precision and innovating concept of a-thermal system, opens the possibility of being implemented in others instruments for large telescopes. 


\section{REFERENCES}

[1] Gil de Paz, A., et al., "MEGARA: the future optical IFU and multi-object spectrograph for the 10.4m GTC telescope", Proc. of SPIE Vol. 8446, 84464Q-1-9 (2012)

[2] Gil de Paz, A., et al., "MEGARA: a new generation optical spectrograph for GTC", Proc. of SPIE, this volume (2014)

[3] Gil de Paz, A, et al., "MEGARA Detailed Design: Instrument Overview", TEC/MEG/106 1.A MEGARA consortium internal technical report, (2014)

[4] Pérez-Calpena, A., et al., "MEGARA focal plane subsystems", Proceedings of the SPIE, Vol. 8446, 84465E84465E-15 (2012)

[5] Maldonado, M., "MEGARA spectrograph for the GTC: mechanical and opto-mechanical design", Proceedings of the SPIE, Vol. 8446, article 844655, 15 pp. (2012)

[6] Castillo-Domínguez, E.; Ferrusca Rodríguez, D.; Tulloch, S.; Velázquez, M., "Cryostat and CCD for MEGARA at GTC", Proc. of SPIE Vol. 8446, 84465Y-1-10 (2012)

[7] Ferrusca, D., Castillo, E., Velázquez, M., et Al., "MEGARA Preliminary Design: Cryostat", TEC/MEG/028 1.D MEGARA consortium internal technical report, 1-50 (2012)

[8] Ferrusca, D., Castillo, E., Velázquez, M., et Al., "MEGARA Detailed Design: Cryostat”, TEC/MEG/104 1.A MEGARA consortium internal technical report, 1-61 (2014)

[9] Bayar, M., "Mechanical design aspects of optomechanical engineering", Proc. of SPIE Vol 0193, $10.1117 / 12.957876,(1979)$

[10] Yoder, P.R., [Opto-mechanical systems design], SPIE press CRC, Washington, 202-204 (2006).

[11] Farah, A., et al, "Optomechanical design, manufacturing, assembly, and integration of contemporary camera barrels for astronomical instrumentation", Optical Engineering, vol. 47, issue 7, p. 073401, (2008)

[12] Carrasco, E. et al, "Optical design for MEGARA: a multi-object spectrograph for the GTC", Proceedings of the SPIE, Volume 8011, article id. 80112D, 10 pp. (2011)

[13] Sánchez, E., Gracía Vargas, M.L., Pérez Calpena, A., "MEGARA Detailed Design: Spectrograph Optics", TEC/MEG/100 2.A MEGARA consortium internal technical report, 1-58 (2013) 